\title{
Antibiotics and antiseptics for preventing infection in people receiving revision total hip and knee prostheses: a systematic review of randomized controlled trials
}

\author{
Jeffrey Voigt ${ }^{1 *}$, Michael Mosier ${ }^{2}$ and Rabih Darouiche ${ }^{3}$
}

\begin{abstract}
Background: Infection rates in revision (second and subsequent) major joint arthroplasty continues to be a significant issue with rates 2-3 times those of primary procedures. The effect of antibiotic and antiseptic prophylaxis on outcomes for this type of surgery has not been adequately reviewed.

Methods: A systematic search of the main databases for randomized controlled trials (RCTs) evaluating antibiotics and antiseptics was conducted to evaluate the predetermined endpoints of infection.

Results: There were five (5) RCTs identified that examined the effects of antibiotic and antiseptic prophylaxis on infections after revision total hip arthroplasty [THA] (total of 304 participants) and total knee arthroplasty [TKA] (total of 206 participants). For TKA, preoperative systemic intravenous (IV) antibiotic prophylaxis plus antibiotic cement may be effective in reducing the incidence of infection in revision TKA at $8+$ years. These results however should be interpreted with caution due to the significant biases. For revision THA, there is no RCT evidence that antibiotics/antiseptics have any effect on the infection rate.

Conclusions: There is a lack of high quality data demonstrating an effect of antibiotics or antiseptics on infection rates in revision THA/TKA. Considering the rate of infections in revisions is 2-3X that of primary procedures and; there is a consensus recommendation to use similar antibiotic and antiseptic regimens in both primary and revision procedures, there is a need for high quality studies in revision THA/TKA.
\end{abstract}

\section{Background}

The use of antibiotic and antiseptic prophylaxis for primary total hip and knee arthroplasty (referred to going forward as THA and TKA) has recently been examined in a systematic review and meta-analysis of randomized controlled trials [1]. In this analysis, it was found that preoperative systemic antibiotic prophylaxis is effective at reducing the infection rate in primary THA (vs. placebo) and that there is no high quality RCT evidence antibiotic prophylaxis is effective at reducing the infection rates in primary TKA. Additionally, it was found that the majority of the US studies examining antibiotic prophylaxis were published back in the 1980s and 1990s. As has been noted,

\footnotetext{
* Correspondence: meddevconsultant@aol.com

'99 Glenwood Rd, Ridgewood, NJ 07450, USA

Full list of author information is available at the end of the article
}

the incidence of diabetes and obesity has increased significantly in these types of patients both for primary and revision THA/TKA $[2,3]$; with diabetes and obesity being known and statistically significant risk factors for infection [4-7]. To date there has not been any sort of systematic review of RCTs examining the effect of antibiotic and antiseptic prophylaxis solely on revision THA and TKA. There have been systematic reviews and meta-analysis that have examined the effect of antibiotic prophylaxis on primary and revision THA/TKA collectively [without separating them out] [8-10]. However, studies also acknowledge the fact that the peri-prosthetic infection rate is $2-3$ times higher in revision THA and TKA than in primary THA/TKA. Additionally, other studies have stated that patients are at a 9-13 times higher risk of infection in a revision TKA/THA procedure than in a primary THA/ TKA [11]. Further, the infection rates in revision THA/ 
TKA have also more than doubled from $1.4 \%$ in the 1991-1994 timeframe to $3.0 \%$ in the 2007-2010 timeframe [3]. Despite the statistically significant higher infection rates seen in revision THA/TKA, surprisingly, the current strong consensus is that perioperative antibiotic prophylaxis should be the same for primary and uninfected revision THA/TKA [12].

The most common organisms for implant infection are Staphylococcus aureus (50-65\%) and Staphylococcus epidermis $(25-30 \%)[13,14]$. However there is also a risk posed by nosocomial (hospital acquired) bacterial infections that are resistant to the antibiotics commonly used prophylactically in implant surgery [15]. These hospital acquired infections include Clostridium difficile (C. diff) and methicillin-resistant Staphylococcus aureus (MRSA). This is especially important in revision procedures as patients undergoing these procedures have an increased risk of developing $C$ diff infections due to their more advanced age and length of hospital stay (relative to primary THA/TKA procedures) [3].

In the US, over the 2006-2012 timeframe (most recent data available on HCUP-Net), there has been a $29 \%$ increase in the number of primary THA and TKA implant procedures going from 700,000 in 2006 to 910,000 in 2012 [16]. During this same timeframe, there has been a $35 \%$ increase in the number of revision THA and TKA implant procedures (complete or partial revision) - going from 75,000 in 2006 to 104,000 in 2012 [16] (See Table 1). This increase in revision procedures in excess of the increase in the number of primary THA and TKA implants is likely due to the prevalence of over 7 million people living with THA and TKAs [17]. A main reason for revision has been due to infection, with approximately $35 \%$ of large joint implants (THA/TKA) being revised for this reason [16].

It is with these issues in mind that a systematic review was undertaken of randomized controlled trials to examine the effect of antibiotics and antiseptics used periprocedurally during the revision THA/TKA procedure. Specifically, the objective of this systematic review was to determine if the application of, types of, route administered, timing, and dosage(s) of antibiotics and antiseptics affected the outcome of infection rates seen post-procedurally in revision THA and TKA.

\section{Methods}

Data sources and searches

The following electronic databases were searched:

- The Cochrane Wounds Group Specialized Register (searched 31 March 2015);

- The Cochrane Central Register of Controlled Trials (CENTRAL; 2015, Issue 3);

- The Database of Abstracts of Reviews of Effects (DARE; 2015, Issue 1);

- The NHS Economic Evaluation Database (NHS EED; 2014, Issue 1);

- Ovid MEDLINE (1948 to March Week 15, 2015);

- Ovid MEDLINE (In-Process \& Other Non-Indexed Citations, 31 March 2015);

- Ovid EMBASE (1980 to 2015 Week 15);

- EBSCO CINAHL (1982 to 31 March 2015);

- Network Digital Library of Theses and Dissertations (NDLTD)

Contacting corresponding authors of included trials was attempted (where updated contact information existed) in addition to the manufacturers and distributors of antibiotics (linezolid, quinupristin/dalfopristin, daptomycin, tigecycline, telavancin and other antistaphylococcal agents and antiseptics). The US Food and Drug Administration (FDA) briefing documents used in the licensing of antistaphylococcal agents was also searched. Citation lists of papers identified by the above strategies for further reports of eligible studies were also checked. The following journals were also hand searched:

- Journal of Bone and Joint Surgery (American volume) (most recent six months up to 4 September 2015; searched on 4 September 2015);

- Journal of Bone and Joint Surgery (British volume) (most recent six months up to 4 September 2015; searched on 4 September 2015);

Table 1 Total joint implants - primary and revision procedures US 2006-2012

\begin{tabular}{|c|c|c|c|c|c|c|c|c|c|c|c|c|}
\hline Year & Prim TKA & $\%$ change & Prim THA & $\%$ change & Rev TKA & $\%$ change & Rev THA & $\%$ change & infection TJA & $\%$ change & $\begin{array}{l}\text { Rev THA/TKA } \\
\text { procedures }\end{array}$ & $\begin{array}{l}\text { \% revision } \\
\text { due to infect }\end{array}$ \\
\hline 2006 & 481,804 & & 221,639 & & 43,746 & & 31,185 & & 26,659 & & 74,931 & $35.6 \%$ \\
\hline 2007 & 532,568 & $10.5 \%$ & 244,247 & $10.2 \%$ & 47,424 & $8.4 \%$ & 34,174 & $9.6 \%$ & 29,210 & $9.6 \%$ & 81,598 & $35.8 \%$ \\
\hline 2008 & 591,493 & $11.1 \%$ & 265,768 & $8.8 \%$ & 56,013 & $18.1 \%$ & 37,474 & $9.7 \%$ & 33,986 & $16.4 \%$ & 93,487 & $36.4 \%$ \\
\hline 2009 & 596,781 & $0.9 \%$ & 274,090 & $3.1 \%$ & 54,592 & $-2.5 \%$ & 36,695 & $-2.1 \%$ & 32,306 & $-4.9 \%$ & 91,287 & $35.4 \%$ \\
\hline 2010 & 631,082 & $5.7 \%$ & 290,959 & $6.2 \%$ & 62,725 & $14.9 \%$ & 41,340 & $12.7 \%$ & 34,469 & $6.7 \%$ & 104,065 & $33.1 \%$ \\
\hline 2011 & 617,823 & $-2.1 \%$ & 293,117 & $0.7 \%$ & 67,061 & $6.9 \%$ & 45,212 & $9.4 \%$ & 37,064 & $7.5 \%$ & 112,273 & $33.0 \%$ \\
\hline 2012 & 610,409 & $-1.2 \%$ & 299,590 & $2.2 \%$ & 62,710 & $-6.5 \%$ & 41,545 & $-8.1 \%$ & 36,650 & $-1.1 \%$ & 104,255 & $35.2 \%$ \\
\hline $\begin{array}{l}\text { Percent chg } \\
2006 \text { to } 2012\end{array}$ & & $26.7 \%$ & & $35.2 \%$ & & $43.4 \%$ & & $33.2 \%$ & & $37.5 \%$ & & \\
\hline
\end{tabular}


- Clinical Orthopedics \& Related Research (most recent six months up to 4 September 2015; searched on 4 September 2015) and;

- Journal of Antimicrobial Agents \& Chemotherapy (most recent six months up to 4 September 2015; searched on 4 September 2015).

Hand searching the journals above was undertaken because of the time lag between their publication and availability on electronic indexes.

In addition, ClinicalTrials.gov on 4 September 2015 were searched to identify any trials in process or recently completed. Google was searched on 4 September 2015 using the search terms: mupirocin, antibiotic, prophylaxis, revision, and orthopedic. The first 8 pages of hits were evaluated.

Search MeSH terms can be found in Additional file 1: Appendix 1. Two review authors screened the titles and abstracts of all studies identified by the search independently. Upon the verbal agreement of both review authors, we obtained full text versions of all studies identified as potentially relevant, and two review authors assessed them independently against the inclusion criteria. Any disagreement(s) between the two review authors were resolved by discussion or adjudicated by a third author.

\section{Study selection}

A systematic review of randomized controlled trials (RCTs) was undertaken that investigated the effect of perioperative antibiotic prophylaxis with or without antiseptics, on outcomes related to surgical site infections (SSIs) during revision THA or TKA replacement. As it relates to definitions used in this analysis, THA/TKA revision procedures are performed for a number of reasons including: mechanical loosening, dislocation, implant failure/breakage, periprosthetic fracture, periprosthetic osteolysis, bearing surface wear, and infection. We did not include revision THA/TKA for infection as the treatment is antibiotics/antiseptics. We were specifically seeking the effect of antibiotic/antiseptic prophylaxis in the future incidence of infection. Additionally, revision THA/TKA procedures are performed to revise all or some of the components that make up the THA/TKA implant. In this analysis we are defining a revision THA as the repeat (second time or more) replacement of: the femoral implant; and/or the acetabular (socket) component and/or; the acetabular liner (composed of different materials but commonly polyethylene). Similarly, revision TKA is defined as the repeat (second time or more) replacement of: the top/upper portion of the tibial bone (tibial component); and/or the tibial insert (composed of polyethylene); and/or the bottom portion of the femoral bone (or femoral condyles termed the femoral component); and/or the patellar components. It also involved the removal of these implants without replacement. Implants that did not meet this definition of THA and TKA were excluded. The years in which antibiotics and antiseptics were first introduced up to the present were considered. All languages were considered. The PRISMA and CONSORT guidelines were followed.

Two review authors screened the titles and abstracts of all studies identified by the search independently. Upon the agreement of both review authors, we obtained full text versions of all studies identified as potentially relevant, and two review authors assessed them independently against the inclusion criteria. Any disagreement(s) between the two review authors were resolved by discussion or adjudicated by a third author. Only full text versions of studies were considered (published or unpublished). Abstracts and conference proceedings were not considered, unless a full length manuscript existed.

\section{Data extraction and study quality assessment}

A data extraction form was developed (See Additional file 1: Appendix 1). One review author extracted the data and a second review author validated the extracted data (performed via written comments and verbally). If a study had more than one publication, all versions were considered in order to maximize data extraction, and the primary publication was identified, along with the secondary references. Where possible, the original investigators were contacted to request the missing data and this was reported on qualitatively.

\section{Assessment of risk of bias in included studies}

Two review authors independently assessed each included study using the Cochrane Collaboration tool for assessing risk of bias [18]. This tool addresses six specific domains, namely sequence generation, allocation concealment, blinding, incomplete outcome data, selective outcome reporting and other issues (e.g. extreme baseline imbalance; see Additional file 1: Appendix 1 for details of the criteria on which judgements were based). Blinding and completeness of outcome data were assessed for each outcome separately. A 'Risk of bias' table was completed for each eligible study. Any disagreement(s) amongst the review authors were discussed to achieve a consensus.

Assessment of risk of bias using a 'Risk of bias' summary figure was evaluated, which presents all of the judgements in a cross-tabulation of study by entry. This display of internal validity indicates the weight the reader may give the results of each study.

A separate examination of the results was reported according to journal of publication and country to determine whether results differed according to the impact of the journal (high versus low [19]; and country (location 
bias [20]. We also assessed studies other than RCTs (i.e. quasi-RCTs) using the same criteria. We incorporated the results of the 'Risk of bias' assessment into the review through systematic narrative description and commentary about each of the domains, leading to an overall assessment of the risk of bias of the included studies and a judgement about the internal validity of the results.

\section{Data synthesis and analysis}

If trials included multiple intervention groups (e.g. different antibiotics), the goal was to split the shared control group into two or more groups with smaller sample sizes, depending upon the number of interventions, and include two or more comparisons.

Authors of papers that we identified only as abstracts were contacted to determine whether the full paper had been published in a peer-reviewed journal or was available from the author as an unpublished draft.

\section{Assessment of reporting biases}

Each primary outcome was reported separately. Furthermore, an assessment of publication bias (including a review of unpublished studies); location bias (types of journals) and language bias was made. The results of trials were examined as favorable or not, with the assumption that favorable results demonstrated a positive effect of antibiotic prophylaxis in lowering the infection rate and thus were published (versus not published) [21]. Location bias refers to more significant results being published in less-respected/low impact factor journals [19]. Lastly, an analysis was made of the reporting of outcomes (reporting bias) as identified below in the 'Risk of bias' tables.

\section{Results}

Results of the search

The electronic searches identified a total of 58 potentially relevant reports. We obtained abstracts for all 58 for further review and evaluation. (See PRISMA Flow Diagram, Fig. 1 for included and excluded studies).

Bibliographic reference checking of a Health Technology Assessment [9], other systematic review articles [8], and of current concept review articles [20,21], identified six additional articles [22-27]. Further hand searching of a Cochrane Review [28] (found through the electronic search) identified an additional study [29]. Hand searching of journals for RCTs also identified three articles [30-32]. Thus a total of ten studies were identified through hand searches.

In total 68 study reports were identified.

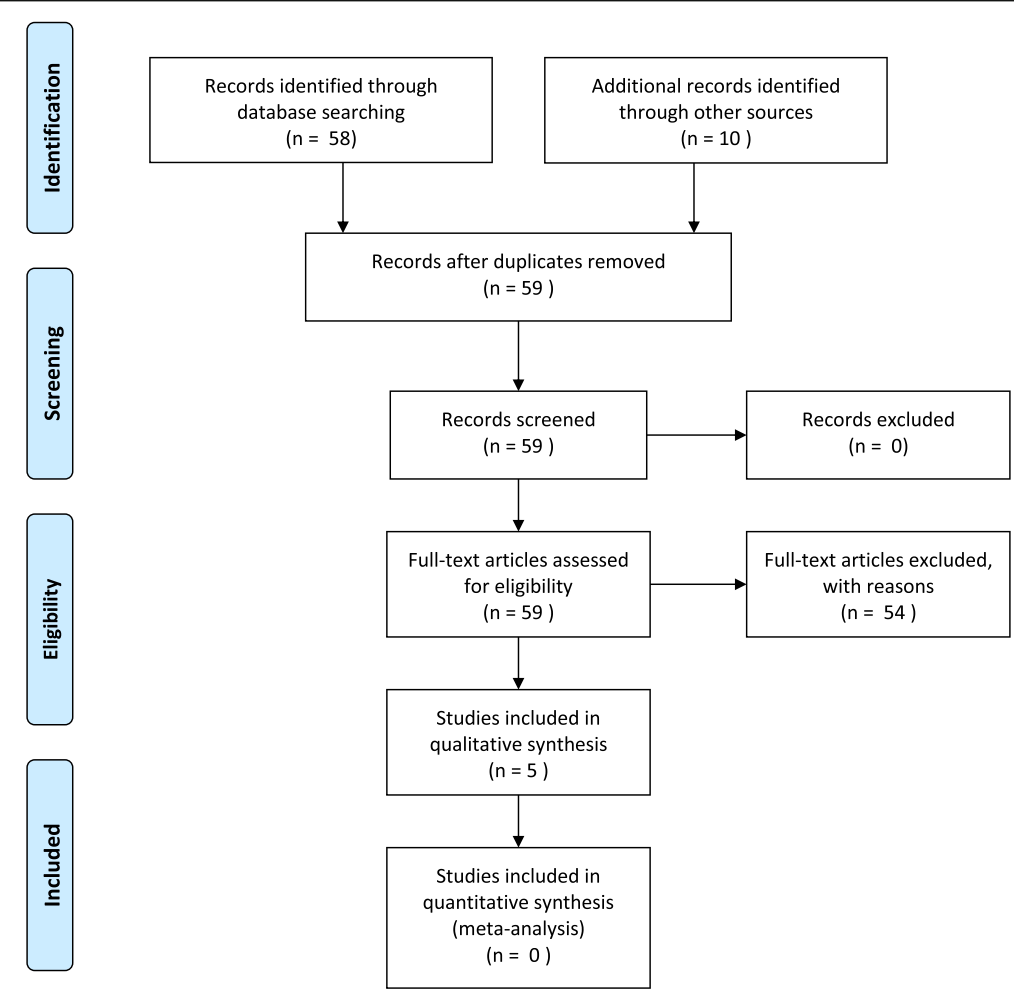

Fig. 1 PRISMA flow diagram 


\section{Included studies}

Five RCTs met the inclusion criteria for the review [33-37]. Two authors were contacted to clarify questions on study design [33] and the breakout of infections by revision THA/TKA [37]. In Chiu [33], both the lead and co-authors never responded to email queries. Phillips [37] responded on 1 September 2015 that he did not have the time to provide additional information (thus a sensitivity analysis was performed on the worst case scenarios to determine if a statistical difference existed). All of the studies except one (Chiu 2009) [33] were conducted in the US. All studies except for one [36] were single center RCTs. Two studies were $>20$ years old $[34,36]$. Table 2 shows a breakout of the studies by: comparison; outcome and total number of patients. In total there were 510 patients.

For the included studies, the comparisons by type of implant, along with summary data on trial design/methodology, sample size, setting, baseline characteristics of patients, and important differences see the Characteristics of the included studies as found in Additional file 2: Appendix 2.

\section{Excluded studies}

\section{Excluded study - characteristics}

Six studies were excluded as they were duplicates of other studies. These duplicates were [32, 38-42]. Thirty one studies were excluded as they were randomized trials performed on primary THA and TKA only [22, 25, 26, 27, 31, 43-67]. Nine studies were excluded due to the fact that the number of revision THA/TKA procedures and corresponding infections could not be broken out from primary THA/TKA $[29,68-75]$. Three studies were excluded as they were for revisions of infected primary THA/TKA and the antibiotics administered were for treatment and not for prophylaxis [76-78]. Three studies were excluded due to the fact that the procedures were not identified as a THA/THA but as an endoprosthesis [79-81]. One study was excluded due to the fact that in the 4 revision THA procedures identified, it could not be determined to which treatment group the patients were allocated to (flucloxacillin or cephaloridine antibiotic prophylaxis [30]. One study was excluded because the procedures being performed were adult orthopedic surgical cases which excluded total joint arthroplasty patients [82]. Lastly, one study was excluded due to it being a retrospective review of the timing of antibiotic prophylaxis [83]. Thus in total 55 studies were excluded with reasons. For further detail on excluded studies, see the Characteristics of excluded studies as found in Additional file 2: Appendix 2 .

\section{Risk of bias in included studies Generation of the randomization sequence}

In the trial with the largest number of patients [33], the risk of bias for randomization was high, considering the use of an "odd-even" allocation. In 3 of the trials, the randomization scheme was clearly identified [35, 36, 37]. In one study, the randomization scheme was unclear [34].

\section{Allocation concealment}

In all of the trials it was unclear as to when allocation to the treatment occurred.

\section{Blinding (performance bias and detection bias)}

In 3 of the trials $[33,35,37]$ the clinician performing the procedures and/or the patient were aware of which treatment group they were allocated to. In 4 of the trials $[33,34,35,36]$ it was unclear if the clinician assessing for the outcome of infection was aware of which treatment group the patient was allocated to.

\section{Incomplete outcome data (attrition bias)}

In 3 of the trials there was a high risk of bias related to attrition of patients on follow up $[33,35,36])$.

\section{Selective reporting (reporting bias)}

In 2 of the studies the risk of selective reporting was high. In DeBenedictis [34], adverse drug reactions identified as an outcome in the methods section were not reported on in the results section. In Phillips 2014, infection and adverse events at 12 months was identified as an endpoint in the methods section but only 3 months

Table 2 Comparisons made in RCTs on the outcome of infection

\begin{tabular}{|c|c|c|c|c|}
\hline \multicolumn{5}{|l|}{ Number patients } \\
\hline Study & Comparison & Outcome & Revision THA & Revision THA \\
\hline Chiu 2009 & Antibiotic impregnated bone cement vs. none & Infection >8 year follow-up & 183 & 0 \\
\hline DeBenedictis 1984 & 1st vs. 2nd generation cephalosporin & Infection 12 months & & 1 \\
\hline Mauerhan 1994 & 1st vs. 2nd generation cephalosporin & Infection 12 months & 62 & 132 \\
\hline Jacobson 2005 & DuraPrep plus loban drape vs. povidone iodine antiseptic & 30 day infection & 11 & 9 \\
\hline Phillips 2014 & $\begin{array}{l}5 \text { day pre-op mupirocin nasal nare application vs. } 2 \text { hour } \\
\text { pre-op povidone iodine antiseptic }\end{array}$ & 3 month infection & 48 & 64 \\
\hline Total & & & 304 & 206 \\
\hline
\end{tabular}




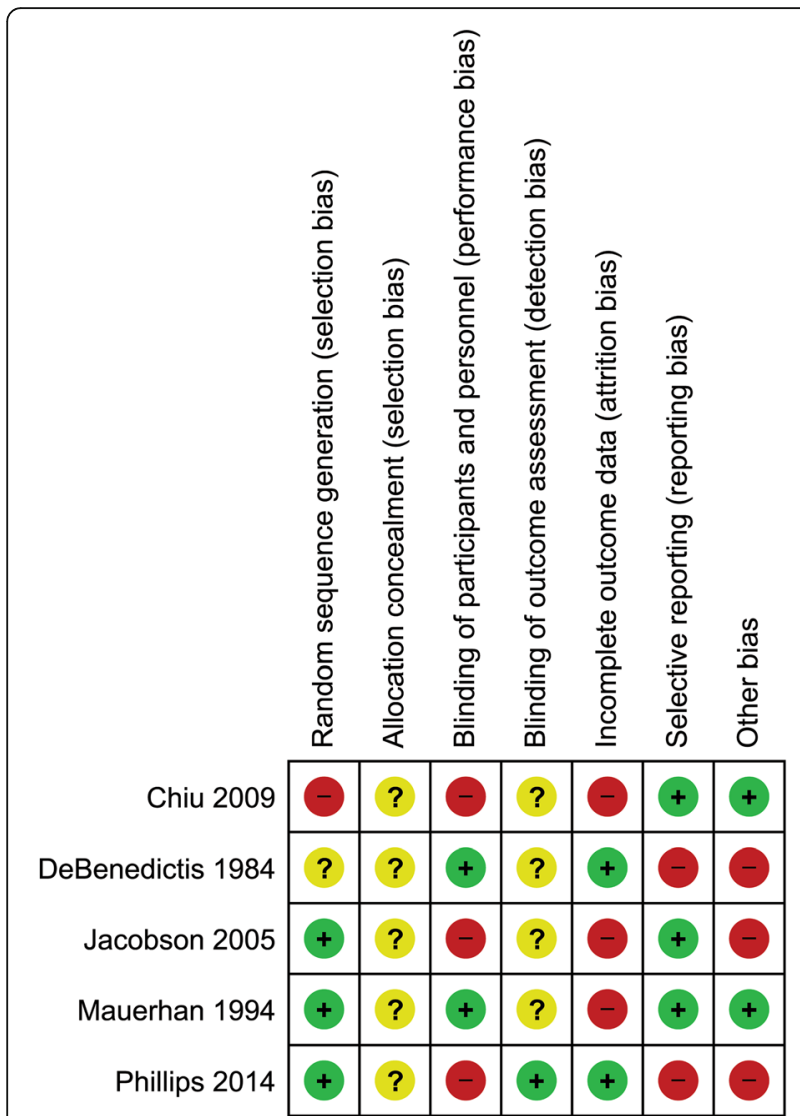

Fig. 2 Risk of bias summary

of follow up on infections and adverse events were reported on in the results section.

\section{Other potential sources of bias}

In 3 of the trials there was a high risk of other bias due to: DeBenedictis 1984 [34] - financial assistance from a manufacturer of one of the antibiotics used; Jacobson 2005 [35] - financial assistance from a manufacturer for the antiseptic used and in the writing of the manuscript; and Phillips 2014 [37] - the manufacturer of one of the products used providing a research grant for the study.

Risk of bias is found in Fig. 2 (Risk of bias summary) and Fig. 3 (risk of bias graph) and; as well Additional file 2: Appendix 2.

\section{Effects of interventions (main outcome of incidence of infection)}

Statistically significant findings (using Fisher exact test) were identified when comparing vancomycin impregnated cement along with IV cefazolin to IV cefazolin in revision TKA procedures [33] $(P=0.0129)$. Nonsignificant findings on the 1 year outcome of infection were identified in comparing 1st generation vs. 2nd generation cefazolin in revision TKA [36] $(\mathrm{RR}=0.29$; $95 \%$ CI: 0.01 to $6.95 ; P=0.45$ ). Further as it relates to the use of mupirocin vs. povidone iodine (PI) nasal antisepsis there was no statistically significant difference in the outcome of infection at 30 days for either revision THA or revision TKA. For this particular analysis, since we were unable to obtain the results from the authors of the article [37] we performed a sensitivity analysis on the incidence of infection in either treatment group (mupirocin vs. PI) using the worst case scenarios on the incidence of infections. In all cases, the differences did not reach statistical significance.

\section{Discussion}

Based on the available data and its relative "poor quality" (i.e. studies with significant biases), no recommendations can be made regarding antibiotic/antiseptic prophylaxis regimens for revision THA/TKA. There is a worrisome lack of data demonstrating any effect of prophylactic antibiotic and antiseptic use on the incidence of infection in revision THA/TKA. In total there were 510 revision THA/TKA patients who could be identified in any sort of randomized trial. Additionally, 183 of these 510 patients come from a trial that is considered poorly designed from a randomization standpoint [18].

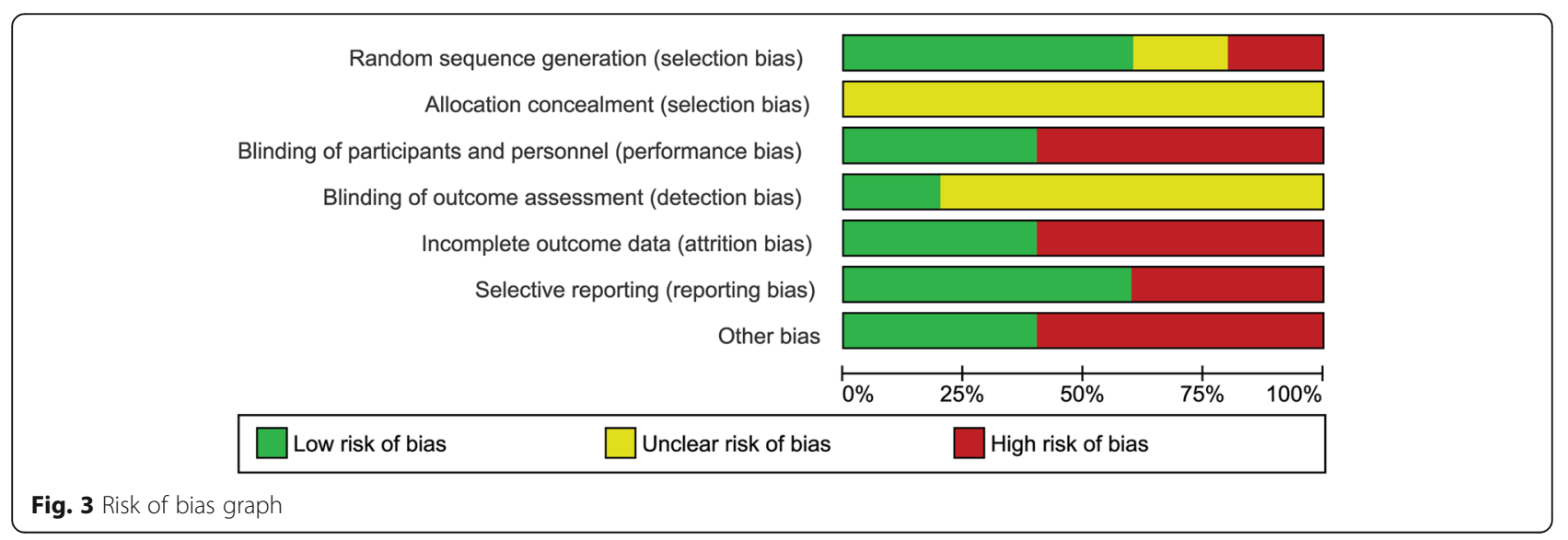


Considering the infection rate in revision THA and TKA is significantly higher than that in primary THA/ TKA $[7,8]$ and; that the consensus recommendation by the Orthopaedic Research Society [12] is that the preoperative antibiotic regimens should be no different between primary and revision THA/TKA - there appears to be no effective prophylaxis regimen(s) that can reduce the infection rate seen in revision THA/TKA. It should be noted that this consensus recommendation has been made using non-randomized studies [12], which thus may render these conclusions questionable.

In the past, the meta-analytic examination of prophylactic antibiotics and antiseptics for preventing infection in primary and revision THA/TKA had not been broken out from primary and revision THA/TKA procedures. For this particular analysis it meant that 9 studies had to be excluded from the overall analysis due to this [29, 68-75]. Additionally, THA and TKA have also not been broken out on the outcome of infection [1] - THA and TKA have traditionally been combined on the outcome of infection. This is also a concern considering the fact that twice as many people receive primary TKA vs. THA; are $20 \%$ heavier and live $25 \%$ longer than they did back in the late 1980s-1990s; are more physically active; that diabetes is 4 times as prevalent in the US vs. 25 years ago [84] and; that diabetes along with obesity are risk factors for infection. [4-7]. This likely means at many patients will outlive their primary THA/TKA, will be sicker and require a revision procedure.

\section{Conclusions}

This analysis supports the contention that more studies need to be initiated examining; what if any antibiotic/antiseptic prophylactic regimen(s) are effective at reducing the infection rate in revision THA/TKA. A potentially reasonable place to start, based on the results from Chiu 2009 [33], is with the use of antibiotic impregnated cement plus IV antibiotics in revision TKA and; engaging in a trial that is randomized appropriately with blinding of clinical assessors (both issues with Chiu 2009 [33]). Further there appears to be some clinical benefit in using antibiotic impregnated bone cement in primary THA or TKA for reducing the infection rate based on a recent systematic review and meta-analysis [85] and in a recent systematic review [10]. These analyses however, included nonrandomized studies but may indicate a potential effect of antibiotic cement in revision THA/TKA [10]. There are also several studies being undertaken which examine the use of intraoperative local antibiotic administration in revision TKA [86] (NCT02020031); preoperative antisepsis in revision THA/TKA [87] (NCT02469311) and; betadine lavage intraoperative and just prior to surgical closure in revision TKA [88] (NCT01175044). The numbers of patients involved in some of these are likely to be too small to demonstrate any statistically significant effect [86]. There are also no studies examining next generation antibiotics specifically for revision THA/TKA. Additional RCT studies on antibiotic/antiseptic prophylaxis in revision THA/TKA should be easier to undertake as the pool of potential patients to include increases each year (Table 1) and the incidence of infections in revision THA/TKA is 2-3 times that of primary THA/TKA $[7,8]$.

\section{Additional files}

Additional file 1: Appendix 1. Search terms and data extraction formR2. (DOCX $25 \mathrm{~kb}$ )

Additional file 2: Appendix 2. Characteristics of included and excluded studies and ongoing studiesR2. (DOCX $123 \mathrm{~kb}$ )

\section{Abbreviations}

C. diff: Clostridium difficile; CENTRAL: Cochrane Central Register of Controlled Trials; CONSORT: Consolidated Standards of Reporting Trials; FDA: Food and Drug Administration; MRSA: Methicillin-resistant Staphylococcus aureus; NDLTD: Network Digital Library of Theses and Dissertations; PRISMA: Preferred Reporting Items for Systematic Reviews and Meta-Analyses; RCT: Randomized controlled trial; SSI: Surgical Site Infection; THA: Total hip arthroplasty; TKA: Total knee arthroplasty

\section{Acknowledgements \\ None. \\ Funding information \\ This research received no funding. All costs in the retrieval, assemblage, analysis, and writing of the manuscript were borne by the authors.}

Availability of data and materials

Additional file 1: Appendix 1: Search terms and data extraction form can be found as a supplementary file

Additional file 2: Appendix 2: Characteristics of included and excluded and ongoing studies can be found as a supplementary file.

\section{Authors' contributions}

$\mathrm{JV}$ and RD developed the question to be answered. JV performed the systematic review along with assistance from the Cochrane Wounds group. $\mathrm{J}, \mathrm{RD}$ and MM agreed upon the articles to be included/excluded along with reasons. JV performed the initial analysis and the draft of the manuscript. RD edited the draft along with MM. MM performed the statistical analyses and detailed the statistical methodology to be used. All authors read and approved the final manuscript.

Competing interests

None to declare.

Consent for publication

Not applicable.

Ethics approval and consent to participate

Not applicable.

\section{Author details}

${ }^{1} 99$ Glenwood Rd, Ridgewood, NJ 07450, USA. Washburn University, Morgan Hall, Room 250 J, 1700 SW College Ave, Topeka, KS 66621, USA. ${ }^{3}$ Michael E. DeBakey Veterans Affairs Medical Center, 2002 Holcombe Blvd \# 128, Houston, TX 77030, USA

Received: 15 February 2016 Accepted: 8 November 2016 Published online: 12 December 2016 


\section{References}

1. Voigt J, Mosier M, Darouiche R. Antibiotics and antiseptics for preventing infection in people receiving primary total hip and knee prostheses: A systematic review and meta-analysis of randomized controlled trials. Antimicrob Agents Chemother. 2015;59(11):6696-707.

2. Cram P, Lu X, Kates SL, Singh JA, Li Y, Wolf BR. Total knee arthroplasty volume, utilization, and outcomes among Medicare beneficiaries, 1991 2010. J Am Med Assoc. 2012;308(12):1227-36.

3. Slover J, Zuckerman JD. Increasing use of total knee replacement and revision surgery. J Am Med Assoc. 2012;308(12):1266-8.

4. Del Pozo JL, Patel R. Infection associated with prosthetic joints. N Eng J Med. 2009;361(8):787-94.

5. Dowsey MM, Choong PFM. Obese diabetic patients are at substantial risk for deep infection after primary TKA. Clin Orthop Relat Res. 2009:467:1577-81.

6. Kurtz SM, Lau E, Schmier J, Ong KL, Zhoa K, Parvizi J. Infection burden for hip and knee arthroplasty in the United States. J Arthroplasty. 2008;23(7):984-91.

7. Peersman G, Laskin R, Davis J, Peterson M. Infection in total knee replacement. Clin Orthop Relat Res. 2001;392:15-23.

8. Albuhairan B, Hind D, Hutchinson A. Antibiotic prophylaxis for wound infections in total joint arthroplasty: a systematic review. J Bone Joint Surg 2008:90-B(7):915-9.

9. Glenny AM, Song F. Antimicrobial prophylaxis in total hip replacement: a systematic review. Health Technol Assess. 1999:3(21):1-57.

10. Parvizi J, Saleh KJ, Ragland PS, Pour AE, Mont MA. Efficacy of antibioticimpregnated cement in total hip arthroplasty. Acta Orthopedica. 2008;79(3):335-41.

11. Ong KL, Lau E, Suggs J, Kurtz SM, Manley MT. Short-term complication risk following primary and revision total joint arthroplasty. 55th Annual Meeting of the Orthopaedic Research Society. 2009; Poster No. 2459

12. Hansen E. Perioperative antibiotics. J Orthop Res. 2014;32:S31-59.

13. Darouiche R. Treatment of infections associated with surgical implants. $N$ Engl J Med. 2004;350:1422-9.

14. Mulcahy $\mathrm{H}$. Chew Current concepts in knee replacement: complications. Am J Roentgenol. 2014;202:W76-86.

15. American Academy of Orthopedic Surgeons. Information statement 1027: Recommendations for the use of intravenous antibiotic prophylaxis in primary total joint arthroplasty. http://www.aaos.org/About/Statements/ Advisements/. (Accessed on 30 Aug 2015).

16. HCUPnet. http://hcupnet.ahrq.gov/ performed on 8/26/15 for primary and revision THA and TKA for the 2006-2012 timeframes.

17. Kremers HM, Larson DR, Crowson CS, Kremers WK, Washington RE, Steiner CA, et al. Prevalence of total hip and knee replacement in the United States. J Bone Joint Surg Am. 2015;97:1386-97.

18. Higgins JPT, Green S (editors). Cochrane Handbook for Systematic Reviews of Interventions 2011; Version 5.1.0 (updated March 2011). The Cochrane Collaboration. Available from http://www.cochranelibrary.com/. Accessed on 30 Aug 2015.

19. Song F, Parekh S, Hooper L, Loke YK, Ryder J, Sutton AJ, et al. Dissemination and publication of research findings: an updated review of related biases. Health Technol Assess. 2010;14(8):1-193.

20. Fletcher N, Sofianos D, Berkes MS, Obremskey WT. Prevention of perioperative infection. J Bone Joint Surg (Am Vol). 2007;89(7):1605-18.

21. Jiranek WA, Hanssen AD, Greenwald AS. Antibiotic-loaded bone cement for infection prophylaxis in total joint replacement. J Bone Joint Surg (Am Vol). 2006;88(11):2487-500.

22. Davis WA, Kane JG. Antimicrobial prophylaxis for arthroplasty: a comparative study of cefonid and cefazolin. Orthopedics. 1987;10(10):1405-9.

23. Josefsson G, Lindberg L, Wicklander B. Systemic antibiotics and gentamicincontaining bone cement in the prophylaxis of postoperative infections in total hip arthroplasty. Clin Orthop Relat Res. 1981;159:194-200.

24. Ritter MA, Campbell E, Keating EM, Faris PM. Comparison of intraoperative versus $23 \mathrm{~h}$ antibiotic prophylaxis in total joint replacement. A controlled prospective study. Orthop Rev. 1989;18(6):694-6.

25. Schulitz KP, Winkelman W, Schoening B. The prophylactic use of antibiotics in alloarthroplasty of the hip joint for coxarthrosis. Arch Orthop Trauma Surg. 1980;96:79-82

26. Soave R, Hirsch JC, Salvati EA, Brause BD, Roberts RB. Comparison of ceforanide and cephalothin prophylaxis in patients undergoing total joint arthroplasty. Orthopedics. 1986;9(12):1657-60.
27. Vainionpää S, Wilppula E, Lalla M, Renkonen OV, Rokkanen P. Cefamandole and isoxazolyl penicillins in antibiotic prophylaxis of patients undergoing total hip or knee joint arthroplasty. Arch Orthop Trauma Surg. 1988;107:228-30.

28. Gillespie WJ, Walenkamp GHIM. Antibiotic prophylaxis for surgery of proximal femoral and other closed long bone fractures. Cochrane Database of Systematic Reviews 2010; Issue 3: Art. No.: CD00024. doi:10.1002/14651858.CD000244.pub2.

29. Van Meir haaeghe J, Verdonk R, Vershraegen G, Myny P, Paeme G, Claessens $H$. Flucloxacillin compared with cefazolin in short-term prophylaxis for clean orthopedic surgery. Arch Orthop Trauma Surg. 1989;108(5):308-13.

30. Pollard JP, Hughes SPF, Scott JE, Evans MJ, Benson MKD. Antibiotic prophylaxis in total hip replacement. Br Med J. 1979;1:707-9.

31. Hill C, Flamant R, Mazas R, Evrard J. Prophylactic cefazolin versus placebo in total hip replacement. Lancet. 1981:8224:795-7.

32. Jones RN, Wokeski W, Bakke J, Porter C, Schwalbe E. Antibiotic prophylaxis of 1036 patients undergoing elective surgical procedures: a prospective randomized comparative trial of cefazolin, cefoxitin, and cefoxatime in a prepaid medical practice. Am J Surg. 1987;153:341-6.

33. Chiu F-Y, Lin C-FJ. Antibiotic-impregnated cement in revision total knee arthroplasty. J Bone Joint Surg. 2009:91-A(3):628-32.

34. DeBenedictis KJ, Rowan NM, Boyer BL. A double blind study comparing cefonid with cefazolin as prophylaxis in patients undergoing total hip or knee replacement. Clin Infect Dis. 1984;6(Supplement 4):S901-904.

35. Jacobson C, Osmon DR, Hanssen A, Trousdale RT, Pagnano MW, Berbari E, et al. Prevention of wound contamination using DuraPrep solution plus loban 2 drapes. Clin Orthop Relat Res. 2005;439:32-7.

36. Mauerhan DR, Nelson CL, Smith DL, Fitzerald RH, Slama TG, Petty RW, et al. Prophylaxis against infection in total joint arthroplasty. J Bone Joint Surg. 1994;76-A(1):39-45.

37. Phillips M, Rosenberg A, Shopsin B, Cuff G, Skeete F, Foti A, et al. Preventing surgical site infections: a randomized, open-label trial of nasal mupirosin ointment and nasal povidone-iodine solution. Infect Control Hosp Epidemiol. 2014;35(7):826-32

38. Carlsson ÄS, Lidgren L, Lindberg L. Prophylactic antibiotics against early and late deep infections after total hip replacement. Acta Orthop Scand. 1977;48:405-10

39. Joseffson G, Gudmundsson G, Kolmert L, Wijkström S. Prophylaxis with systemic antibiotics versus gentamicin bone cement in total hip arthroplasty. Clin Orthop Relat Res. 1990;253:173-8.

40. Josefsson G, Kolmert L. Prophylaxis with systemic antibiotics versus gentamicin bone cement in total hip arthroplasty. Clin Orthop Relat Res. 1993;292:210-4

41. McQueen M, Littlejohn A, Hughes SPF. A comparison of systemic cefuroxime and cefuroxime loaded bone cement in the prevention of early infection after total joint replacement. Int Orthop. 1987;11:241-3.

42. Bode LGM, Kluytmans JAJW, Wertheim HFL, Bogaers D, VandenbrouckeGrauls CMJE, Roosendaal R, et al. Preventing surgical-site infections in nasal carriers of Staphylococcus aureus. NEJM. 2010;362(1):9-17.

43. Adalberth G, Nilsson KG, Kärrholm J, Hassander H. Fixation of the tibial component using CMW-1 or Palacos bone cement with gentamicin. Acta Orthop Scand. 2002;73(5):531-8.

44. Bohm E, Petrak M, Gascoyne T, Turgeon T. The effect of adding tobramycin to Simplex $\mathrm{P}$ cement on femoral stem micromotion as measure by radiostereometric analysis. Acta Orthop. 2012;83(2):115-20.

45. Chareancholvanich $K$, Udomkiat $P$, Waikukul S. A randomized controlled trial between fosfomycin and cefuroxime as the antibiotic prophylaxis in knee arthroplasty. J Med Assoc Thail. 2012;95(Supplement 9):S6-S13.

46. Chiu FY, Lin C-FJ, Chen CM, Lo WH, Chaung T-Y. Cefuroxime-impregnated cement at primary total knee arthroplasty in diabetes mellitus. J Bone Joint Surg Br Vol. 2001;83(5):691-5.

47. Chiu F-Y, Chen C-M, Lin C-FJ, Lo WH. Cefuroxime-impregnated cement in primary total knee arthroplasty. J Bone Joint Surg (Am Vol). 2002;84(5): 759-62.

48. De Lalla F, Novelli A, Pellizer G, Milocchi F, Viola F, Rigon A, et al. Regional and systemic prophylaxis with teicoplanin in monolateral and bilateral total knee replacement procedures: study of pharmacokinetics and tissue penetration. Antimicrob Agents Chemother. 1993;37(12):2693-8.

49. Ericson C, Lindgren $L$, Lindberg L. Cloxacillin in the prophylaxis of postoperative infections of the hip. J Bone Joint Surg. 1973:55-A:808-13.

50. Evard J, Doyon F, Acar JF, Salord JC, Mazas F, Flamant R. Two-day cefamandole versus five-day cephazolin prophylaxis in 965 total hip replacements. Int Orthop. 1988;12:69-73. 
51. Friedman RJ, Friedrich LV, White RL, Kays MB, Brundage DM, Graham J. Antibiotic prophylaxis and tourniquet inflation in total knee arthroplasty. Clin Orthop Relat Res. 1990;260:17-23.

52. Gunst JP, Deletang S, Rogez JM, Blanloeil Y, Baron D, Dixneuf B. Prophylactic antibiotic therapy with cefamandole in total hip surgery replacement using Charnley's tent. A randomized study [Antibiothérapie prophylactique par le céfamandole dans la chirurgie de al prosthèse totale de hanche sous tente de charnley]. Pathol Biol. 1984;32(5):567-9.

53. Hinarejos P, Guirro P, Leal J, Montserrat F, Pelfort X, Sorli ML, et al. The use of erythromycin and colistin-loaded cement in total knee arthroplasty does not reduce the incidence of infection. J Bone Joint Surg. 2013;95:769-74.

54. Johnson DP. Antibiotic prophylaxis with cefuroxime in arthroplasty of the knee. J Bone Joint Surg Br Vol. 1987;87:787-9.

55. Kanellakopoulou K, Papadopoulos A, Varvaroussis D, Varvaroussis A, Giamerollos-Bourboulis EJ, Pagonas A, Stergiou A, Papedelis P, Nikolaidis V, Giamarellou H. Efficacy of teicoplanin for the prevention of surgical site infections after total hip or knee arthroplasty: a prospective, open-label study. Int J Antimicrob Agents. 2009;33:437-330.

56. McQueen MM, Hughes SPF, May P, Verity L. Cefuroxime in total joint arthroplasty. J Arthroplasty. 1990;5(2):169-72.

57. Mollan RA, Haddock M, Webb CH. Teicoplanin versus cephamandole for antimicrobial prophylaxis in prosthetic joint implant surgery: preliminary results. Eur J Surg. 1992;567(Supplement):19-21.

58. Morrison TN, Taneja M, Purtill JJ, Austin M, Parvizi J. Prospective, randomized, blinded study to evaluate two surgical skin preparations in reducing SSI after TJA. Prospective, randomized, blinded study to evaluate two surgical skin preparations in reducing SSI after TJA. AAOS Annual Meeting, Final Program 2014; (Paper 049):63.

59. Petiri $P$, Stringa G, Mini E. Comparative multicenter trial of teicoplanin versus cefazolin for antimicrobial prophylaxis in prosthetic implant surgery. Eur J Clin Microbiol Infect Dis. 1999;18:113-9.

60. Richardson JB, Roberts A, Robertson JFR, John PJ, Sweeney G. Timing of antibiotic administration in knee replacement under tourniquet. J Bone Joint Surg Br Vol. 1993;735-B:32-5.

61. Soriano A, Bori G, García-Ramiro S, Martinez-Pastor JC, Miarna T, Codina C, et al. Timing of antibiotic prophylaxis for primary total knee arthroplasty performed during ischemia. Clin Infect Dis. 2008;46:1009-14.

62. Suter F, Avai A, Fusco U, Gerundini M, Caprioli S, Maggiolo F. Teicoplanin versus cefamandole in the prevention of infection in total hip replacement. Eur J Clin Microbiol Infect Dis. 1994;13(10):793-6.

63. Tyllianakis ME, Klarageorgos AC, Marangos MN, Saridis AG, Lambiris EE. Antiobiotic prophylaxis in primary hip and knee arthroplasty. J Arthroplasty. 2010;25(7):1078-82.

64. van den Brand ICJB, Castelein RM. Total joint arthroplasty and incidence of postoperative bacteriuria with and indwelling catheter or intermittent catheterization with one-dose antibiotic prophylaxis. J Arthroplasty. 2001; 16(7):850-5.

65. van Rijen MML, Bode LGM, Baak DA, Kluytmans JAJW, Vos MC. Reduced costs for Staphylococcus aureus carriers treated prophylactically with mupirocin and chlorhexidine in cardiothoracic and orthopedic surgery. PLoS ONE. 2012;7(8), e43065.

66. Young SW, Ahang M, Freeman JT, Vince KG, Coleman B. Higher cefazolin concentrations with intraosseous regional prophylaxis in TKA Clinical Orthopaedics and Related Research. 2012; doi:10.1007/s11999012-2469-2.

67. Young SW, Zhang M, Freeman JT, Mutu-Grigg J, Pavlou P, Moore GA. The Mark Coventry Award. Higher tissue concentrations of vancomycin with low-dose intraosseous regional versus systemic prophylaxis in TKA. A randomized trial. Clin Orthop Relat Res. 2014;472:57-65.

68. Bryan CS, Morgan SL, Caton RJ, Lunceford EM. Cefazolin versus cefamandole for prophylaxis during total joint arthroplasty. Clin Orthop Relat Res. 1988; 228:117-22.

69. Gilliam DL, Nelson CL. Comparison of a one-step iodophor skin preparation versus traditional preparation in total joint surgery. Clin Orthop Relat Res. 1990;250:258-60

70. Jones RN, Wojeski WV. Single-dose surgical prophylaxis using ticarillin/ clavulanic acid (TimentinTM). A prospective randomized comparison with cefoxatime. Diagn Microbiol Infect Dis. 1987;7:219-23.

71. Jones RN, Slepack JM, Wojeski W. Cefoxatime single-dose surgical prophylaxis in a prepaid group practice. Comparisons with other cephalosporins and ticarcillin/clavulanic acid. Drugs. 1988;35(Supplement 2):116-23.
72. Lidwell OM, Lowbury EJL, Whyte W, Blowers R, Stanley SJ, Lowe D. Infection and sepsis after operations for total hip or knee-joint replacement: influence of ultraclean air, prophylactic antibiotics and other factors. J Hygiene. 1984; 93(3):505-29.

73. Liebergall M, Mosheiff R, Rand N, Peyser A, Shaul J, Kahane Y. A double-blinded, randomized, controlled trial to compare cefazolin and cefonicid for antimicrobial prophylaxis in clean orthopedic surgery. Isr J Med Sci. 1995;31:62-4.

74. Nelson CL, Green TG, Porter RA, Warren RD. One day versus seven days of preventive antibiotic therapy in orthopedic surgery. Clin Orthop Relat Res. 1983;176:258-63.

75. Periti P, Stringa G, Donati L, Mazzei T, Mini E, Novelli A. Teicoplanin - its role as systemic therapy of burn infections and as prophylaxis for orthopaedic surgery. Eur J Surg. 1994;564:3-8.

76. Byren I, Rege S, Campanaro E, Yankelev S, Anastasiou D, Kuropatkin G, et al. Randomized controlled trial of the safety and efficacy of daptomycin versus standard-of-care therapy for management of patients with osteomyelitis associated with prosthetic devices undergoing two-stage revision arthroplasty. Antimicrob Agents Chemother. 2012;56(11):5626-32.

77. Tetreault MW, Wetters NG, Aggarwal V, Mont M, Parvizi J, Della Valle CJ. Should prophylactic antibiotics be withheld before revision surgery to obtain appropriate cultures? Clin Orthop Relat Res. 2014;472:52-6.

78. Zimmerli W, Widmer AF, Blatter M, Frei R, Ochsner PE. 1998. Role of rifampin for treatment of orthopedic implant-related staphylococcal infections. J Am Med Assoc. 1998;279:1537-41.

79. Garcia S, Lozano ML, Gatell JM, Soriano E, Ramon R, Sanmiguel JG. Prophylaxis against infection. Single-dose cefonicid compared with multiple-dose cefamandole. J Bone Joint Surg. 1991;73-A(7):1044-8.

80. Wall R, Klenerman L, McCullough C, Fyfe I. A comparison of teicoplanin and cefuroxime as prophylaxis for orthopedic implant surgery: a preliminary report. J Antimicrob Chemother. 1998;21(Supplement A):141-6.

81. Winter M, Ungemach J, Glicksman H. Flucloxacillin and ceftriaxone in the perioperative prophylaxis of patients undergoing hip and knee surgery by a prospective randomized trial. Chemiotherapia. 1987;6(2 Supplement):577.

82. Zdeblick TA, Lederman MM, Jacobs MR, Marcus RE. Peroperative use of povidone-iodine. Clin Orthop Relat Res. 1986;213:211-5.

83. van Kasteren MEE, Manniën J, Ott A, Kullbery B-J, de Boer AS, Gyssens IC. Antibiotic prophylaxis and the risk of surgical site infections following total hip arthroplasty: timely administration is the most important factor. Clin Infect Dis. 2007:44:921-7.

84. Centers for Disease Control and Prevention. National diabetes fact sheet: national estimates and general information on diabetes and prediabetes in the United States. U.S. Department of Health and Human Services, Centers for Disease Control and Prevention (accessed on 10 Sept 2015).

85. Wang J, Zhu C, Cheng T, Peng X, Zhang W, Qin H, et al. A systematic review and meta-analysis of antibiotic impregnated cement use in primary total hip or knee arthroplasty. PLoS One. 2013;8(12):e82745. doi:10.1371/journal. pone.0082745

86. NCT02020031. Regional prophylactic vancomycin in revision total knee replacement (VIDACARE). Accessed on 10 Sept 2015 at: https://linicaltrials.gov/

87. NCT02469311. Prospective, randomized study evaluating the efficacy of chlorhexidine gluconate impregnated no-rinse cloths (SAGE). Accessed on 10 Sept 2015 at: https://clinicaltrials.gov/

88. NCT01175044. 2015. Dilute betadine lavage in the prevention of postoperative infection. Accessed on 10 Sept 2015 at: https://clinicaltrials.gov/

\section{Submit your next manuscript to BioMed Central and we will help you at every step:}

- We accept pre-submission inquiries

- Our selector tool helps you to find the most relevant journal

- We provide round the clock customer support

- Convenient online submission

- Thorough peer review

- Inclusion in PubMed and all major indexing services

- Maximum visibility for your research

Submit your manuscript at www.biomedcentral.com/submit 